Tema: Aciaria Elétrica

\title{
REDUÇÃO DO ÍNDICE DE MISTURAS DE ESCÓRIAS GERADAS NA ACIARIA DA APERAM*
}

\section{Resumo}

Bruno Cordeiro Costa ${ }^{1}$ Hélcio de Araújo Quintão ${ }^{2}$ Hugleslei Vagner Mendonça ${ }^{3}$ Isnard de Miranda Cadastro ${ }^{4}$ Janeir Ribeiro Dutra ${ }^{5}$ José Eustáquio Pinto ${ }^{6}$ Márcio Siqueira da Silva ${ }^{7}$ Marconi da Silva Carvalho ${ }^{8}$ Wanderson Silva Marques ${ }^{9}$

Inseridas em um mercado extremamente competitivo, as empresas siderúrgicas vêm buscando aprimorar seus processos produtivos e de gestão de forma a reduzir custos de produção e garantir sua sustentabilidade. A principal parcela do custo de produção da empresa em relação a um aço inoxidável ligado ao Cromo e Níquel está na Aciaria, e a carga metálica representa mais de $80 \%$ deste valor. Visando aumentar a competitividade, foi aberto um projeto para otimizar a carga metálica na Aciaria. A redução da mistura de escórias é uma fase deste projeto. O propósito do presente trabalho é mostrar a metodologia adotada para otimizar o processo de recuperação de sucata das escórias de aços inoxidáveis, minimizando a ocorrência de misturas de escórias, para maximizar seus teores de $\mathrm{Ni}$ e $\mathrm{Cr}$ e, consequentemente, reduzir o uso de fontes mais nobres e caras destes elementos. Foi adotada a filosofia "Zero de Escória no Chão" e, para alcançar este objetivo, várias ações foram implantadas. Considerando 2011 como base 100\%, o teor médio de Ni da sucata recuperada de 3XX aumentou 45\% em 2013 e o teor médio de $\mathrm{Cr}$ subiu $36 \%$ na sucata recuperada neste mesmo período. Como consequência direta da redução da mistura de escórias de grupos de aços diferentes ao longo de todo fluxo produtivo, ocorre a redução dos residuais de $\mathrm{Ni}$ e $\mathrm{Cr}$ nos aços carbono e elétricos e de $\mathrm{Ni}$ nos aços $4 \mathrm{XX}$. A metodologia adotada foi eficiente e os objetivos do projeto foram alcançados.

Palavras-chave: Teores de $\mathrm{Cr}$ e Ni das sucatas recuperadas.

\begin{abstract}
REDUCTION OF THE CONTENT OF MIXTURES OF GENERATED SLAG IN APERAM'S MELTSHOP Abstract

Inserted in an extremely competitive market, steel companies are seeking to enhance their production and management processes to reduce costs and ensure its sustainability. The main portion of the company production cost regarding stainless steel alloyed on Chromium and Nickel are in Meltshop and the metallic charge represents more than $80 \%$ of this value. In order to increase competitiveness, was created a project to optimize the metal charge on Meltshop. The reduction of the mixture of slag is a phase of this project. The purpose of this work is to show the methodology used to optimize the process of recovering scrap from stainless steel slag, minimizing the occurrence of mixtures of slag to maximize their levels of $\mathrm{Ni}$ and $\mathrm{Cr}$, and consequently reduce the use of more sources noble and expensive of these elements. The "Zero Slag on the floor" philosophy was adopted and to accomplish this, several actions were implemented. Considering 2011 as a $100 \%$ basis, the average Ni content in recovered 3XX scrap increased $45 \%$ in 2013 and the average Cr content increase $36 \%$ in the scrap recovered in the same period. As a direct consequence of the slag mixture reduction throughout steel production flow the residual levels of $\mathrm{Ni}$ and $\mathrm{Cr}$ on electrical and carbon steels was reduced and $\mathrm{Ni}$ in 4XX steel was also reduced. The methodology adopted was efficient and the project objectives were achieved.
\end{abstract}

Keywords: Levels of $\mathrm{Cr}$ and $\mathrm{Ni}$ in recovered scrap.

1 Engenheiro de produção, Coordenador do Pátio de Metálicos, Gerência de Fornos Elétricos, Aperam South America, Timóteo, MG, Brasil.

Engenheiro Metalurgista, Gerência de Aciaria, Aperam South America, Timóteo, MG, Brasil.

Gestor de produção industrial, Gerência de Fornos Elétricos, Aperam South America, Timóteo, MG, Brasil.

Administrador de empresas, Gerente Executivo, Gerência de Suprimentos, Aperam South America, Timóteo, MG, Brasil.

Engenheiro de Materiais, Gerência de Fornos Elétricos, Aperam South America, Timóteo, MG, Brasil.

6 Administrador de empresas, Assistente Técnico, Gerência de convertedores, Aperam South America, Timóteo, MG, Brasil.

7 Administrador de empresas, Gerente, Gerência de Fornos Elétricos, Aperam South America, Timóteo, MG, Brasil.

8 Administrador Comércio Exterior, Analista Suprimentos de Materiais, Gerencia de Suprimentos, Aperam South America, Timóteo, MG, Brasil.

9 Técnico Metalúrgico, Técnico Controle de Processo, Gerencia de Fornos Elétricos, Aperam South America, Timóteo, MG, Brasil.

\footnotetext{
* Contribuição técnica ao 45 Seminário de Aciaria - Internacional, 25 a 28 de maio de 2014, RS, Brasil.

Porto Alegre, 


\section{INTRODUÇÃO}

Os aços inoxidáveis têm como principal propriedade a resistência a corrosão, contendo acima de $10,5 \%$ de cromo além de outros elementos de liga, tais como níquel, molibdênio, manganês, silício, etc. Os elementos de ligas são adicionados para adequar o aço as necessidades de aplicação, melhorando suas características e propriedades metalúrgicas, físicas, químicas e mecânicas. Os aços inoxidáveis podem ser classificados em austeníticos, martensíticos e ferríticos, dependendo da composição química e microestrutura.

A maior parte dos aços austeníticos se enquadra no grupo chamado popularmente de $18-8$, em que o teor médio de cromo é $18 \%$ e o de níquel $8 \%$. A introdução do níquel no aço melhora consideravelmente a resistência à corrosão e a resistência à oxidação a altas temperaturas, visto que, na maioria dos reagentes, o níquel é mais nobre que o ferro e, além disso, forma uma camada de óxido que protege o aço espontaneamente, neste caso a restauração da película inerte protetora que tenha sido retirada de um aço inoxidável ao Cr-Ni é muito mais rápida do que a de um aço inoxidável somente ao cromo.

Tendo em vista que o custo de produção deste aço na Aciaria representa $86 \%$ do custo total da empresa, e que na Aciaria o custo da carga metálica equivale a aproximadamente $90 \%$ deste valor, foi aberto um projeto para otimizar a carga metálica na Aciaria e a redução da mistura de escória é uma fase deste projeto.

O propósito do presente trabalho é mostrar a metodologia adotada para otimizar o processo de recuperação de sucata das escórias de aços inoxidáveis, minimizando a ocorrência de misturas de escórias, para maximizar seus teores de $\mathrm{Ni}$ e $\mathrm{Cr}$ e conseqüentemente reduzir o uso de fontes mais nobres destes elementos.

\section{OBJETIVO}

Minimizar a ocorrência de misturas de escórias ao longo de todo fluxo produtivo da Aciaria para maximizar os teores de $\mathrm{Ni}$ e $\mathrm{Cr}$ nas sucatas recuperadas, e conseqüentemente reduzir o custo de produção das placas pela substituição de fontes mais nobres de $\mathrm{Cr}$ e Ni.

\section{DESENVOLVIMENTO}

\subsection{Fluxo de Produção da Aciaria}

A Figura 1 mostra o fluxo produtivo Aciaria da Aperam. Que tem os seguintes equipamentos PTG (Estação de tratamento de Gusa), FEA's (Forno elétrico a arco), AOD-L (Descarburação com oxigênio e Argônio), MRPL (Processo de refino metal com lança), VOD (Descarburação com oxigênio e vácuo, FP (Forno Panela), LC (Lingotamento Continuo) e ESM (Esmerilhadeira de Placa. Observa-se que na mesma planta ocorre a produção simultânea de aços inoxidáveis com altos teores de $\mathrm{Cr}$ e $\mathrm{Ni}$ e aços Carbono e Elétricos GO e GNO com restrições fortes destes elementos.

Durante o processo de produção de aço na Aciaria a geração de escória varia de 300 a $500 \mathrm{~kg}$ de escória para cada tonelada de aço lingotado, e esta escória contém em torno de $10 \%$ de metal que deve retornar ao processo na forma de sucata recuperada da escória.

* Contribuição técnica ao 45 Seminário de Aciaria - Internacional, 25 a 28 de maio de 2014, 
cuidado para que as escórias geradas em cada grupo de aços não se misturem, garante uma melhor qualidade da sucata recuperada, com melhor aproveitamento dos elementos de liga e menor risco de contaminação dos aços baixa liga.

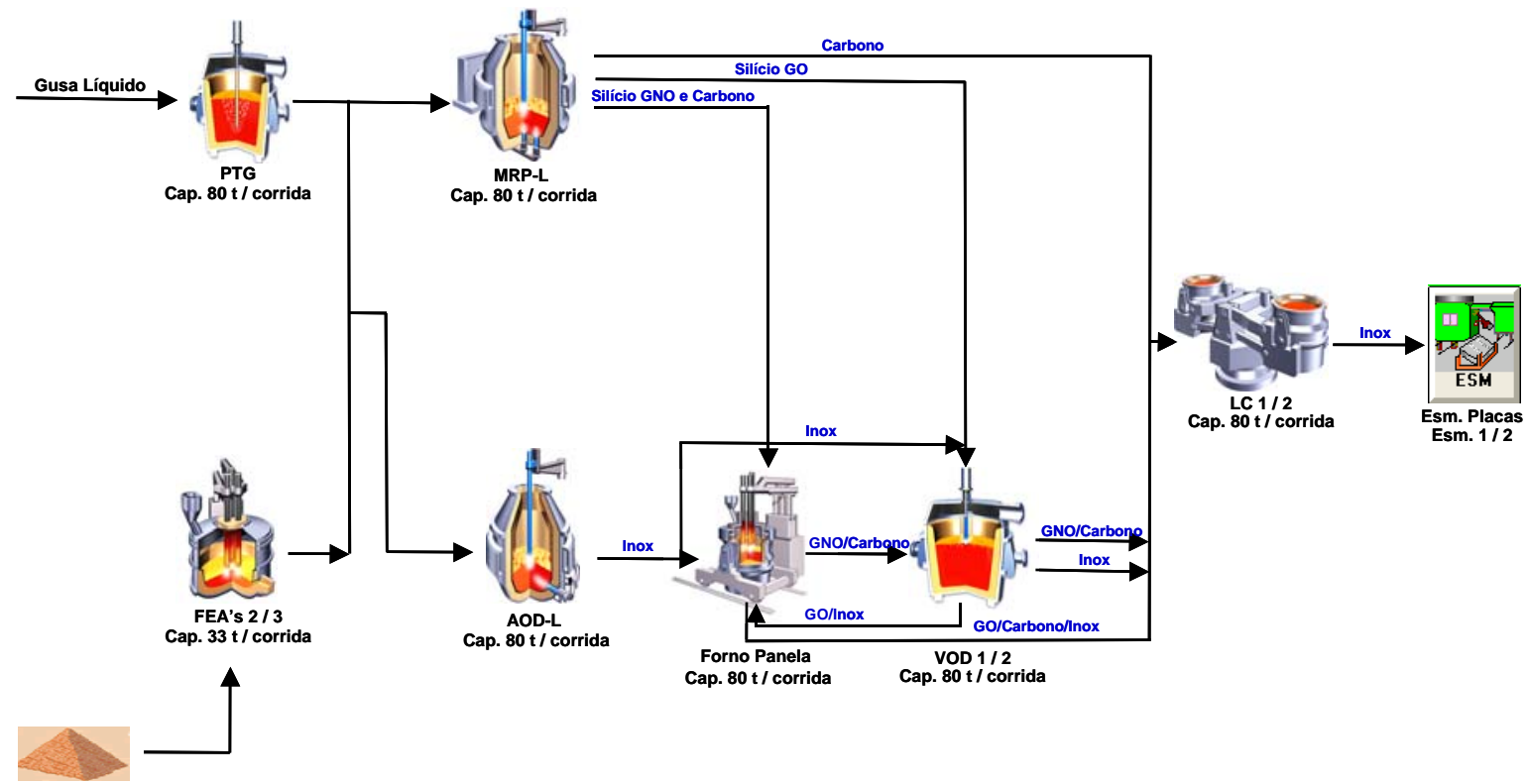

Figura 1. Fluxo de produção da Aciaria da Aperam.

As Figuras 2 e 3 mostram os fluxos de escórias geradas na produção dos aços inoxidáveis e Carbono/Elétricos.
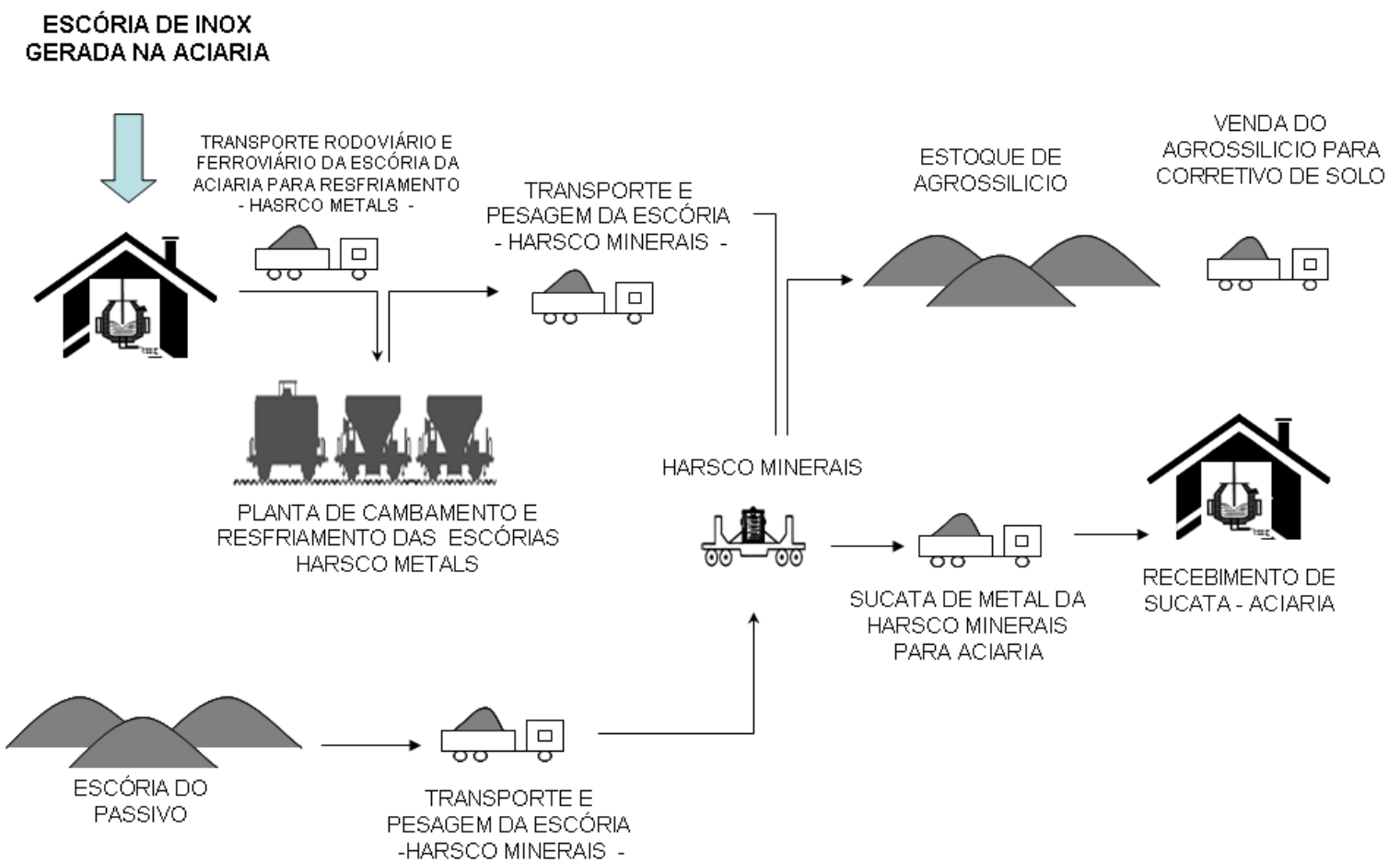

Figura 2. Fluxo de escória de Inoxidáveis.

* Contribuição técnica ao $45^{\circ}$ Seminário de Aciaria - Internacional, 25 a 28 de maio de 2014, Porto Alegre, RS, Brasil. 


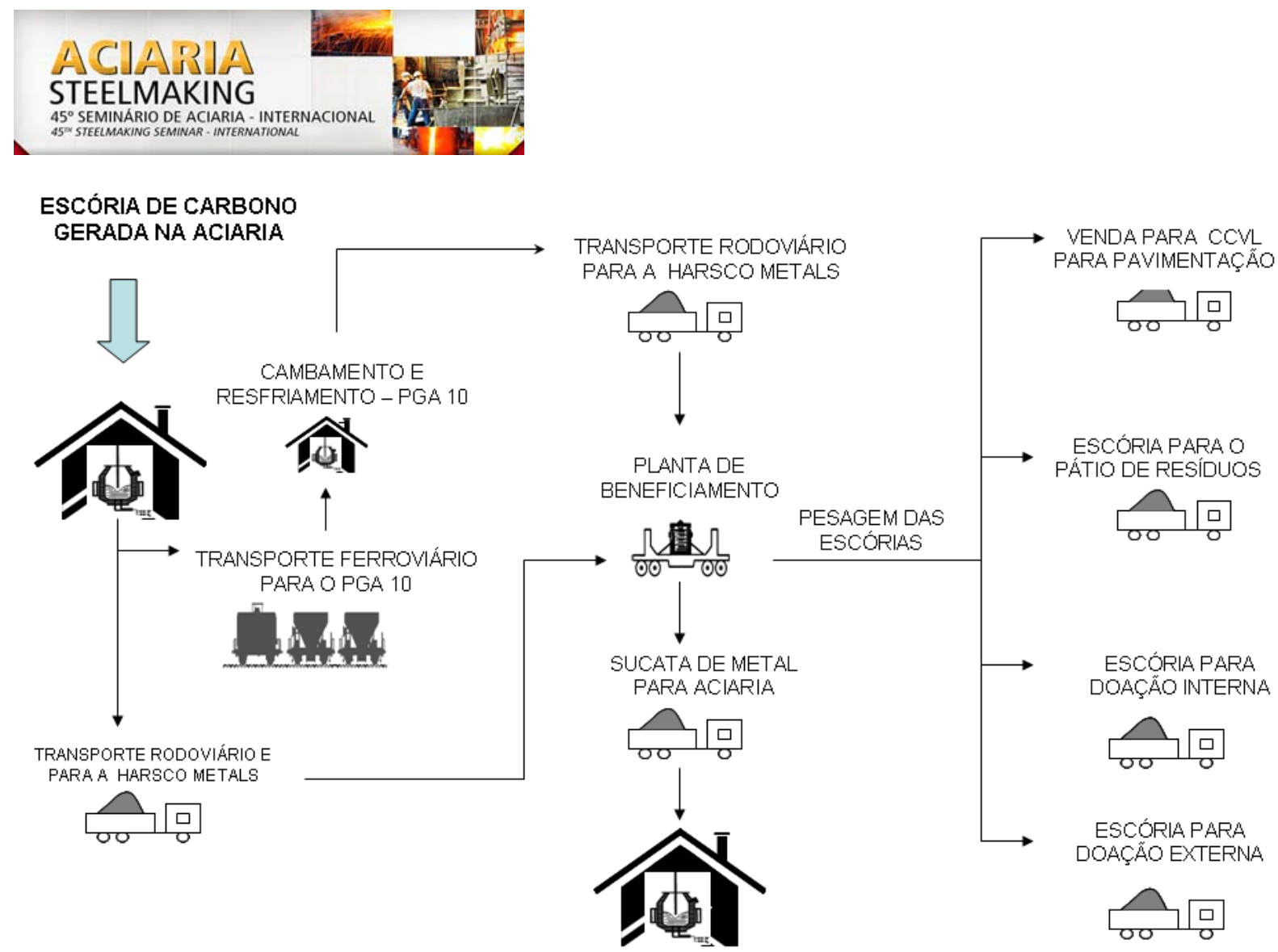

Figura 3. Fluxo de escória de Carbono e Elétricos.

Observa-se a existência de uma grande movimentação de material por transporte ferroviário e rodoviário, o que ressalta a necessidade dos cuidados ao longo de todo fluxo para evitar as misturas de escórias de diferentes grupos de aço.

\subsection{Contextualização}

A Figura 4 mostra que o custo da fase Aciaria representa $86 \%$ do custo total da produção do aço 304A - 2,00mm.

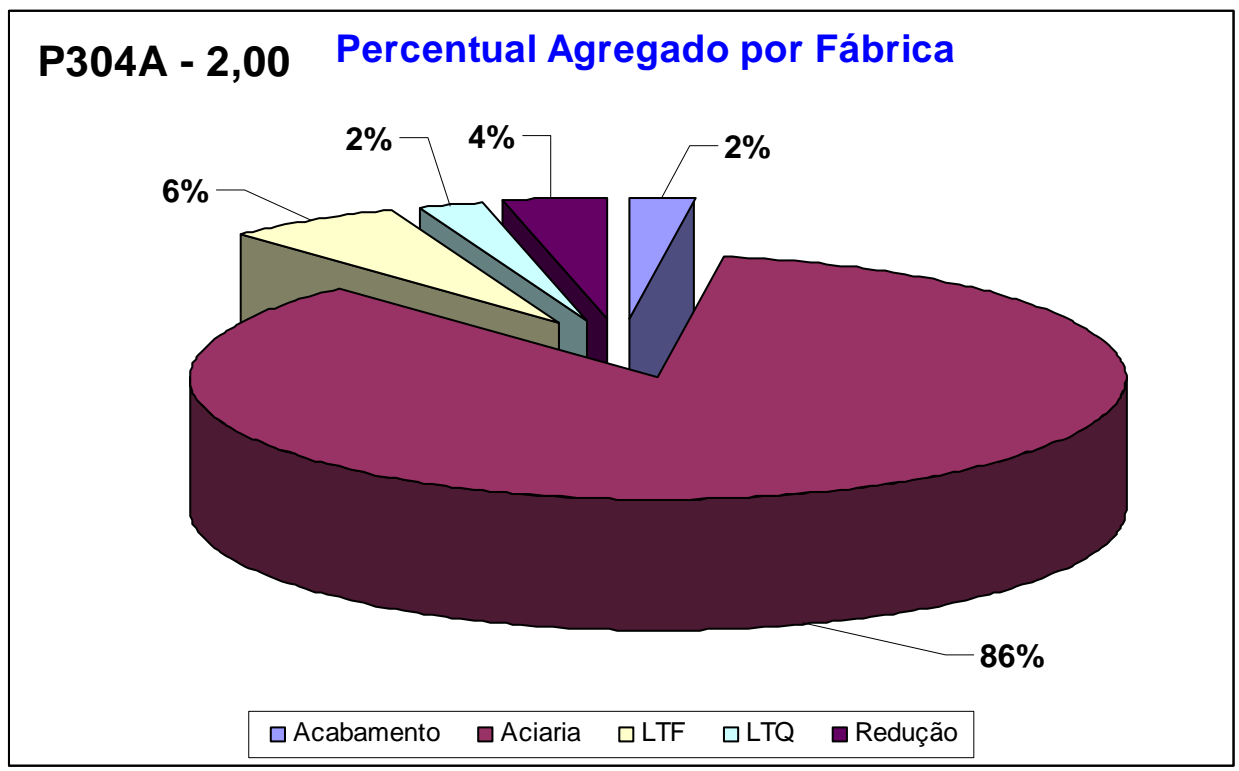

Figura 4. Percentual de custo agregado no P304A 2,00 mm por fábrica.

* Contribuição técnica ao 450 Seminário de Aciaria - Internacional, 25 a 28 de maio de 2014, Porto Alegre, RS, Brasil. 
$\mathrm{Na}$ busca do aumento da competitividade da Aperam, foi solicitado o desenvolvimento de um grande projeto para otimizar a carga metálica da Aciaria, tendo em vista que esta representa $90 \%$ do custo da aciaria.

A Figura 5 mostra a estruturação do projeto de carga metálica na Aciaria, que tem como um dos objetivos na fase 1 eliminar a mistura de escória de Aciaria.

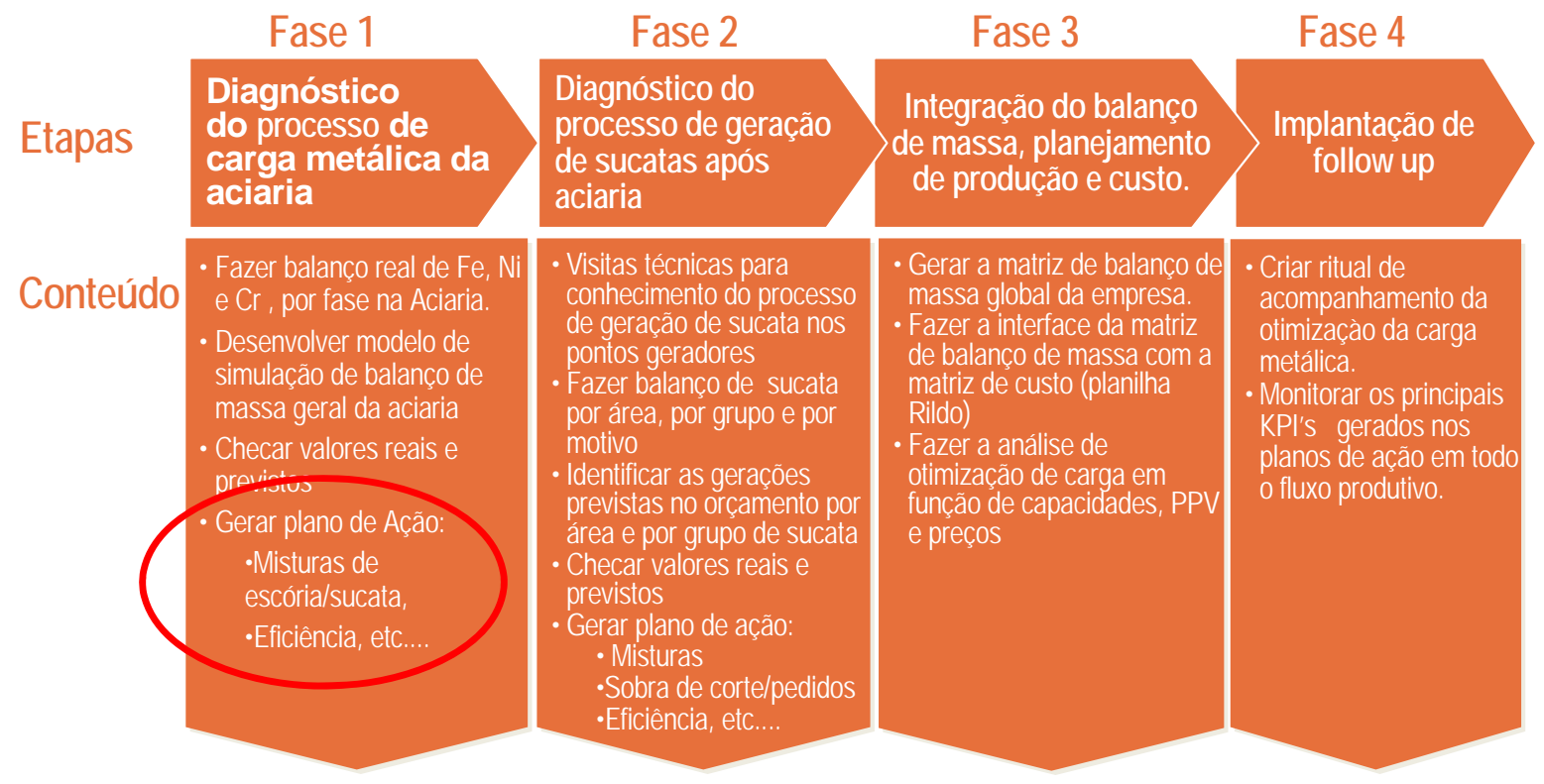

Figura 5. Estruturação do projeto carga metálica da Aciaria.

A sucata recuperada de escória com o teor de $\mathrm{Ni}$ mais elevado, significa melhor aproveitamento do Ni que já está no fluxo e menor necessidade de $\mathrm{Ni}$ de fontes de maior custo.

\subsection{Metodologia de Trabalho}

Para minimizar a ocorrência da mistura de escórias de diferentes grupos de aço, foi adotada a filosofia "Zero de escória no chão", e para alcançar este objetivo, as principais ações podem ser citadas:

- Recomposição do número de potes necessários para coleta de escória separados por ponto de geração;

- Adequação do PGA 10 (Antigo Galpão do Forno elétrico de redução) para cambagem e resfriamento de escória de Carbono e elétricos;

- Adequação da linha férrea do PGA 70 (Local de cambagem de Escória dos LC's nos potes) para transporte de escória com potes grandes;

- Implantação de reunião diária de acompanhamento com todos os envolvidos no processo;

- Implantação do fiscal de campo responsável pelo processo ao longo de todo fluxo produtivo, etc.

A Figura 6 mostra o relatório de acompanhamento do projeto com outras ações.

* Contribuição técnica ao $45^{\circ}$ Seminário de Aciaria - Internacional, 25 a 28 de maio de 2014, 


\begin{tabular}{|c|c|c|c|c|c|c|}
\hline \multicolumn{7}{|c|}{ RELATÓRIO MENSAL DE ACOMPANHAMENTO DO PROJETO } \\
\hline (2) & $\begin{array}{c}\text { Projeto: } \\
\text { Responsável: }\end{array}$ & \multicolumn{5}{|c|}{$\begin{array}{l}\text { Reduzir o indice de mistura de escórias geradas pela Aciaria } \\
\text { Bruno Cordeiro / Joel Medeiros }\end{array}$} \\
\hline \multirow[b]{2}{*}{ ETAPAS } & \multirow[b]{2}{*}{ RESP. } & \multirow{2}{*}{\multicolumn{2}{|c|}{ PRAZO }} & & & \\
\hline & & & & \multicolumn{2}{|r|}{ Status } & Farol \\
\hline $\begin{array}{l}\text { Retirar todo volume de escórias existentes na Aciaria e } \\
\text { encaminhar para o Pátio de Escórias }\end{array}$ & Joel & $15 / 07 / 2011$ & $10 / 08 / 2011$ & $100 \%$ & $100 \%$ & Bom \\
\hline $\begin{array}{l}\text { Processar todo o volume de escórias existentes no Pátio de } \\
\text { Escória interno da usina com o objetivo de "zerar" o seu } \\
\text { passivo }\end{array}$ & Joel & $15 / 07 / 2011$ & 15/08/2011 & $100 \%$ & $100 \%$ & Bom \\
\hline \begin{tabular}{|l|} 
Alterar frequência de limpeza das baias de escórias da \\
Aciaria pela Harsco
\end{tabular} & Márcio Siqueira & $01 / 08 / 2011$ & $10 / 08 / 2011$ & $100 \%$ & $100 \%$ & Bom \\
\hline $\begin{array}{l}\text { Instituir reuniôes de followup entre representantes da } \\
\text { Aperam e Harsco }\end{array}$ & Márcio Siqueira & $15 / 07 / 2011$ & $15 / 08 / 2011$ & $100 \%$ & $100 \%$ & Bom \\
\hline $\begin{array}{l}\text { Criar rotina mecanizada para aferir o volume teórico de } \\
\text { geraçấo de escória e o real recebido no Pátio de Escórias }\end{array}$ & Cláudio Teixeira & $05 / 08 / 2011$ & $15 / 09 / 2011$ & $100 \%$ & $100 \%$ & Bom \\
\hline $\begin{array}{l}\text { Revisar o procedimento documentado NTA } 09 \text { - } 0004 \\
\text { "Controle de Bodes" e divulgar para os envolvidos. }\end{array}$ & Bruno & $25 / 10 / 2011$ & $31 / 03 / 2012$ & $100 \%$ & $100 \%$ & Bom \\
\hline $\begin{array}{l}\text { Criação de baía para escória "Mista" na área externa da } \\
\text { Aciaria. }\end{array}$ & Bruno & $01 / 03 / 2012$ & $10 / 04 / 2012$ & $100 \%$ & $100 \%$ & Bom \\
\hline $\begin{array}{l}\text { Dimensionar KPI's para os contratos da Harsco Metals e da } \\
\text { Harsco Minerais pertinentes a este projeto }\end{array}$ & Bruno & $10 / 08 / 2012$ & $20 / 09 / 2013$ & $96 \%$ & $100 \%$ & Bom \\
\hline Separação dos potes por equipamentos & José Eustáquio & $20 / 08 / 2012$ & $30 / 09 / 2012$ & $100 \%$ & $100 \%$ & Bom \\
\hline $\begin{array}{l}\text { Montar açónes juntamente com a Harsco para organizar as } \\
\text { baias interna na aciaria para acompanhamento diário. }\end{array}$ & José Eustáquio & $04 / 08 / 2012$ & $31 / 12 / 2012$ & $100 \%$ & $100 \%$ & Bom \\
\hline $\begin{array}{l}\text { Fazer auditórias nas baias aciarias uma vez por semana } \\
\text { com espectrômetro. }\end{array}$ & Joel & $01 / 09 / 2012$ & $31 / 12 / 2012$ & $100 \%$ & $100 \%$ & Bom \\
\hline Separar baias mistas da Aciaria (lixo Aciaria) & José Eustáquio & $01 / 10 / 2012$ & $15 / 10 / 2012$ & $100 \%$ & $100 \%$ & Bom \\
\hline Rever procedimento de Forração de Potes & José Eustáquio & $01 / 10 / 2012$ & $31 / 12 / 2012$ & $100 \%$ & $100 \%$ & Bom \\
\hline $\begin{array}{l}\text { Separar escória da Baia do Forno Panela na campanha } \\
\text { Triplex enviando para } 4 \times x \text { e quando normal para Carbono }\end{array}$ & José Eustáquio & $01 / 10 / 2012$ & $15 / 10 / 2012$ & $100 \%$ & $100 \%$ & Bom \\
\hline $\begin{array}{l}\text { Preparar as baias do Ling. Contínuo na campanha em dois } \\
\text { fornos }(3 \times x \text { e } 4 \times x \text { ou nâo fazer inox dois fornos } \\
3 x \times \text { e } 4 \times x\end{array}$ & José Eustáquio & $01 / 10 / 2012$ & $15 / 10 / 2012$ & $100 \%$ & $100 \%$ & Bom \\
\hline $\begin{array}{l}\text { Criar a função fiscal de campo até dezembro para } \\
\text { acompanhamento do fluxo de escória na aciaria. }\end{array}$ & Marcio/Hélcio & $01 / 11 / 2012$ & $22 / 12 / 2012$ & $100 \%$ & $100 \%$ & Bom \\
\hline $\begin{array}{l}\text { Retiradas de Cascốes da Baia somente com autorizaçấo da } \\
\text { Aperam. }\end{array}$ & Wanderson & $01 / 11 / 2012$ & $15 / 12 / 2012$ & $100 \%$ & $100 \%$ & Bom \\
\hline $\begin{array}{l}\text { Mudar Lay Out baias Planta de Escória, evitando } \\
\text { contaminaçẫo do Lixo de carbono com gusa. }\end{array}$ & Wanderson & $01 / 11 / 2012$ & 15/12/2012 & $100 \%$ & $100 \%$ & Bom \\
\hline $\begin{array}{l}\text { Capacitar, treinar equipe da Harsco quanto ao processo de } \\
\text { remoçâo e destinaçâo de escórias e cascóes da aciaria. }\end{array}$ & Wanderson & $01 / 11 / 2012$ & & & & Bom \\
\hline $\begin{array}{l}\text { Fazer o acompanhamento da planta verso geração de } \\
\text { escórias. }\end{array}$ & Wanderson & $01 / 11 / 2012$ & & & & Bom \\
\hline $\begin{array}{l}\text { Utilizar somente escória de } 4 \times \times \text { para secar á area em frente } \\
\text { as baias de cambamento e transformar em mista. }\end{array}$ & Bruno/Joel & $01 / 12 / 2012$ & $15 / 12 / 2012$ & $100 \%$ & $100 \%$ & Bom \\
\hline $\begin{array}{l}\text { Garantir a forraçấo das baias com o tipo de material que } \\
\text { está sendo cambado. }\end{array}$ & Bruno/Joel & $01 / 12 / 2012$ & $15 / 12 / 2012$ & $100 \%$ & $100 \%$ & Bom \\
\hline $\begin{array}{l}\text { Garantir a preparação das leiras com o tipo de material que } \\
\text { está sendo cambado. }\end{array}$ & Bruno/Joel & $01 / 12 / 2012$ & $15 / 12 / 2012$ & $100 \%$ & $100 \%$ & Bom \\
\hline Amostrar, analisar todo lote de sucata recuperada & Wanderson & $15 / 04 / 2013$ & $15 / 06 / 2013$ & $100 \%$ & $100 \%$ & Bom \\
\hline
\end{tabular}

Figura 6. Relatório mensal de acompanhamento do projeto.

\section{RESULTADO E DISCUSSÂO}

\subsection{Teor de Ni e Cr na Sucata Recuperada 3XX}

As Figuras 7 e 8 mostram as evoluções dos teores médios de $\mathrm{Ni}$ e $\mathrm{Cr}$ da sucata recuperada de 3XX para o período de 2011 a jun/2013.

O teor médio de Ni da sucata recuperada de 3XX aumentou 44\% comparando 2011 com 2013, com atendimento à meta em todos os meses de 2013. O teor médio de Cr subiu no mesmo período $36 \%$.

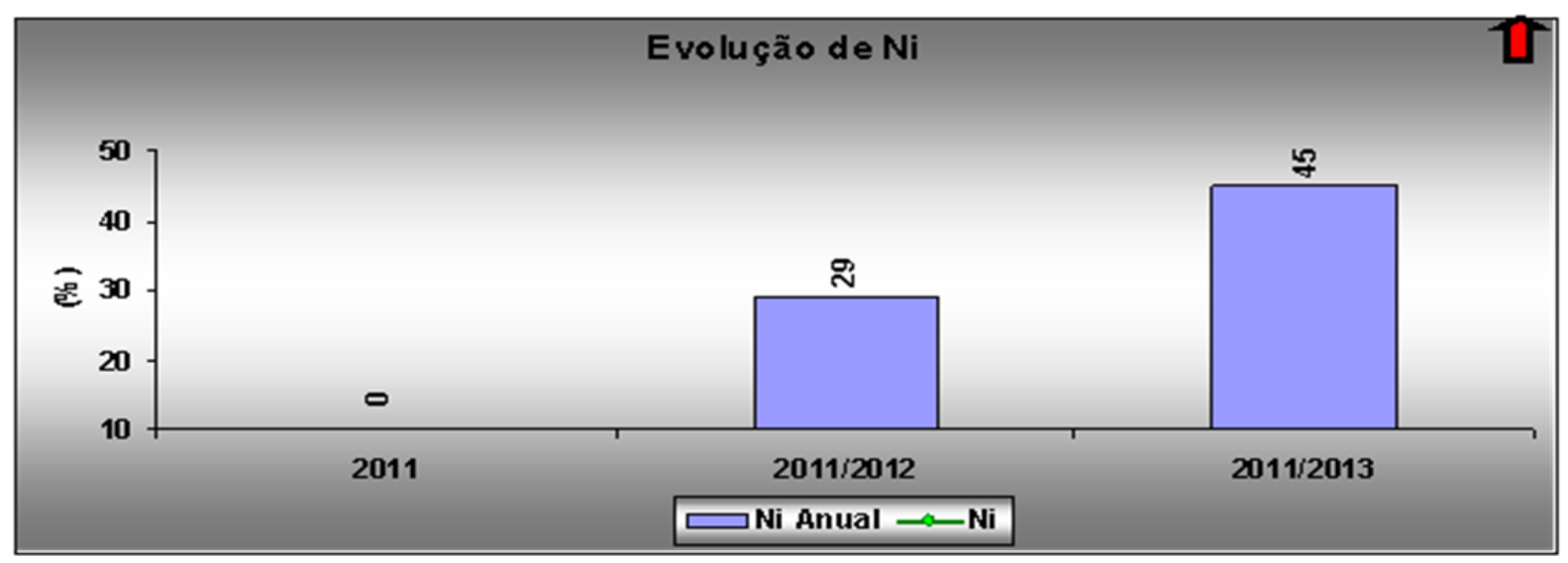

Figura 7. Evolução do teor de Ni nas sucatas recuperadas de 3XX.

* Contribuição técnica ao $45^{\circ}$ Seminário de Aciaria - Internacional, 25 a 28 de maio de 2014, Porto Alegre, RS, Brasil. 

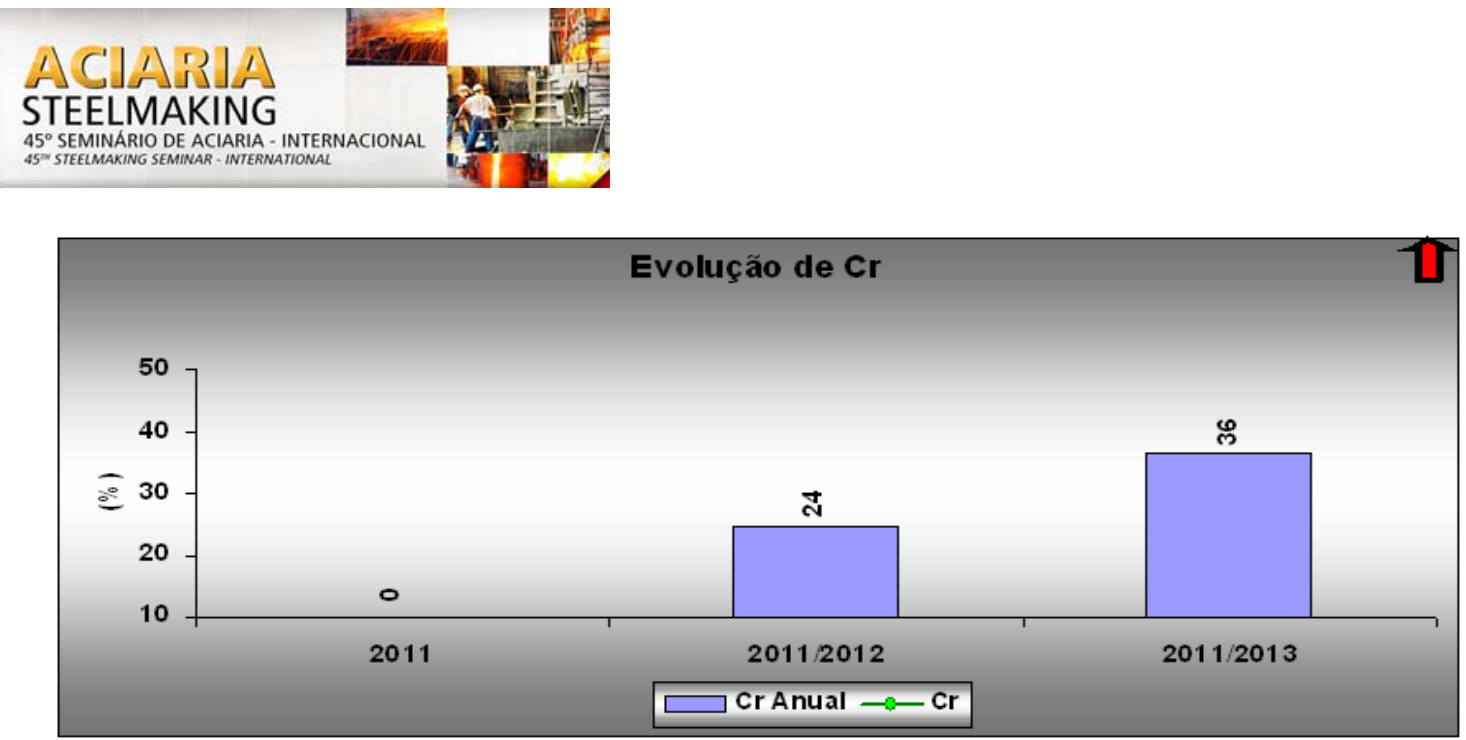

Figura 8. Evolução do teor de $\mathrm{Cr}$ nas sucatas recuperadas de 3XX.

\subsection{Teor de Ni e Cr Residual no GNO e 430A}

Como consequência direta da redução da mistura de escórias de grupos de aços diferentes ao longo de todo fluxo produtivo, ocorre a redução dos residuais de $\mathrm{Ni}$ e $\mathrm{Cr}$ nos aços carbono e elétricos e de Ni nos aços 4XX. As Figuras 9 e 10 mostram que o residual médio de Ni no GNO caiu de 0,020\% em 2011para 0,009\% médio nos 6 primeiros meses de 2013 e o residual de $\mathrm{Cr}$ apresentou a mesma tendência para este aço no período, caindo de 0,079\% para 0,054\% médios.

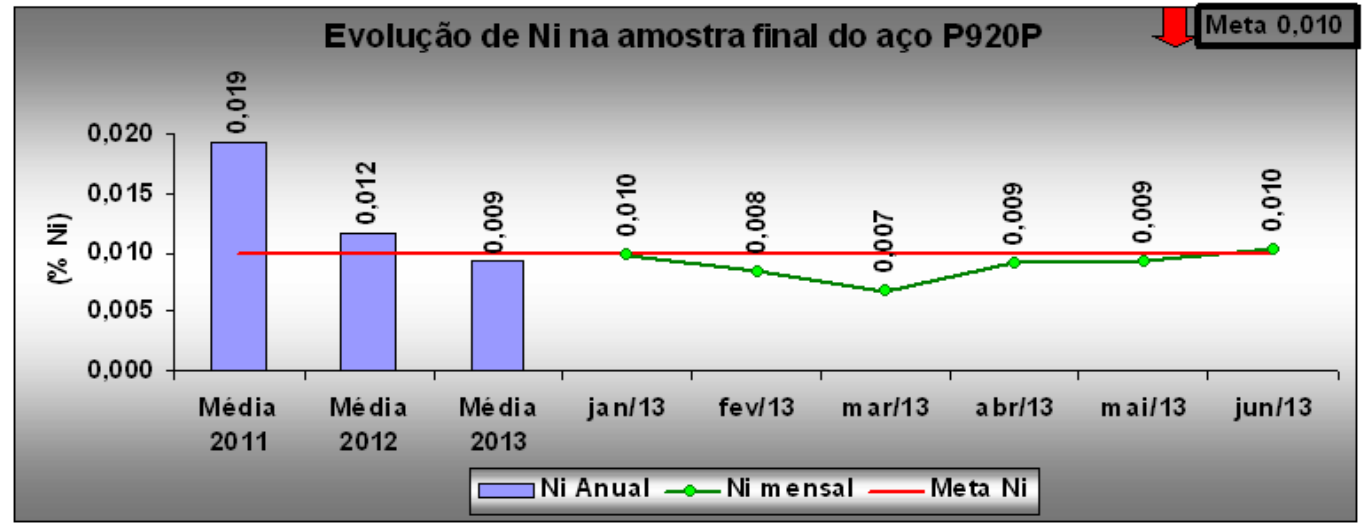

Figura 9. Evolução do teor residual de Ni no GNO - P920P.

A Figura 10 mostra o mesmo efeito no residual médio de Ni no P430A que caiu de 0,23\% em 2011para 0,21\% médio nos 6 primeiros meses de 2013.

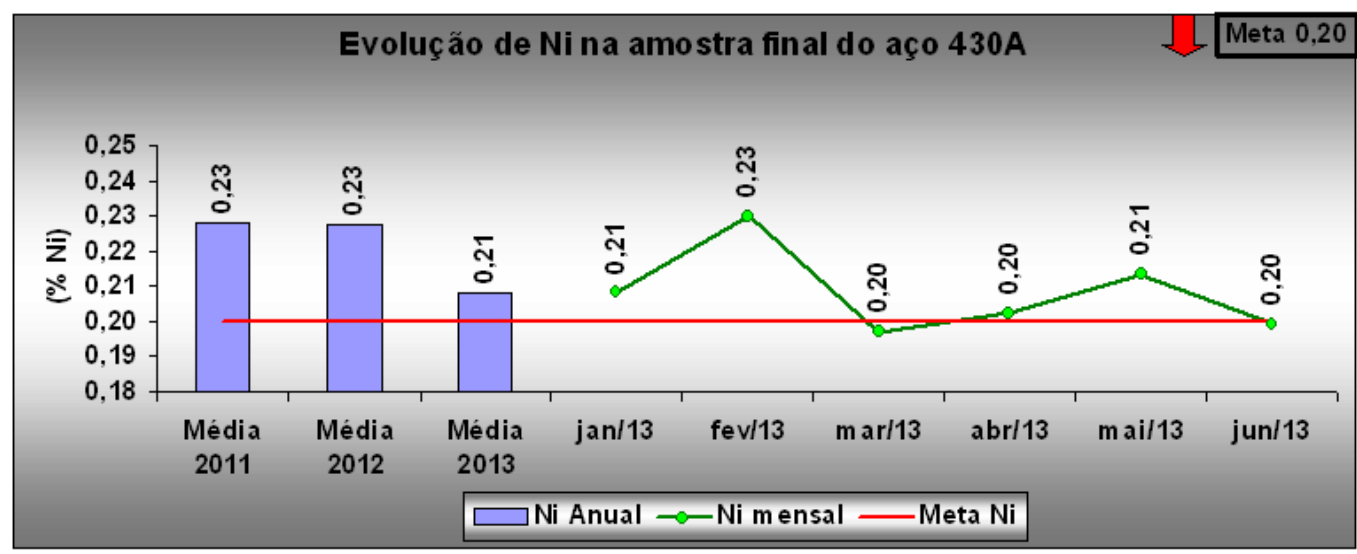

Figura 10. Evolução do teor residual de Ni no aço P430A.

* Contribuição técnica ao 450 Seminário de Aciaria - Internacional, 25 a 28 de maio de 2014, 


\subsection{Análise de Custo}

A Figura 11 mostra a variação de eficiência do consumo de sucata recuperada de 3XX no balanço de Ni da carga.

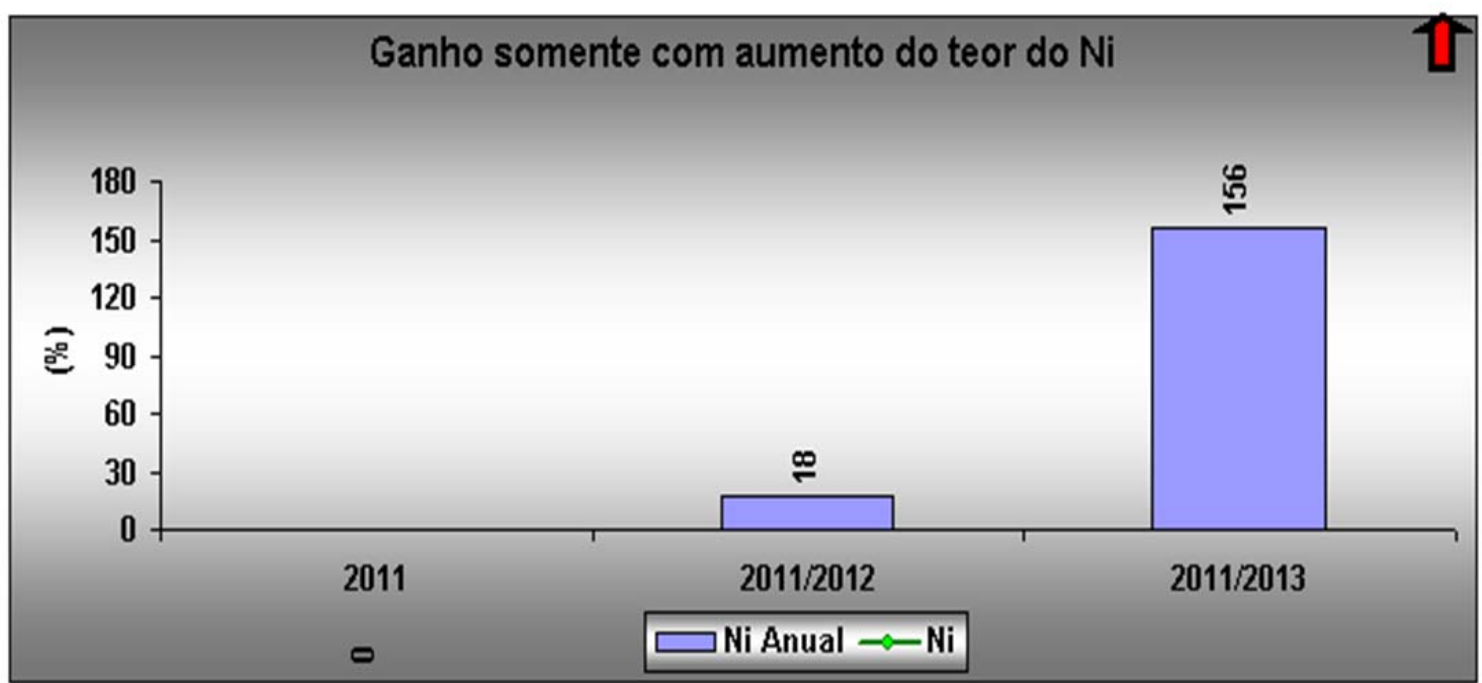

Figura 11. Variação de Eficiência do consumo de sucata recuperada de 3XX no balanço de Ni.

Observa-se que teve uma evolução na variação de eficiência de 18\% comparando o ano de 2011 com 2012 e de 156\% comparando 2011 com 2013.

\section{CONCLUSÔES}

A filosofia adotada "Zero de escória no chão" foi eficiente e os objetivos do projeto foram alcançados.

A recomposição do número de potes necessários para coleta de escória separados por ponto de geração, a adequação do PGA 10 (antigo galpão do forno elétrico de redução) para cambagem e resfriamento de escória de Carbono e elétricos, a adequação da linha férrea do PGA 70 (Local de cambagem de Escória dos LC's nos potes) para transporte de escória com potes grandes, a implantação das reuniões diárias de acompanhamento com todos os envolvidos no processo, e a implantação do fiscal de campo responsável pelo processo ao longo de todo fluxo produtivo foram de fundamental importância para o sucesso deste trabalho.

O teor médio de Ni da sucata recuperada de 3XX aumentou 44\% comparando 2011 com 2013, com atendimento à meta em todos os meses de 2013. O teor médio de Cr subiu no mesmo período $36 \%$.

Como consequência direta da redução da mistura de escórias de grupos de aços diferentes ao longo de todo fluxo produtivo, ocorre a redução dos residuais de $\mathrm{Ni} \mathrm{e}$ Cr nos aços carbono e elétricos e de Ni nos aços 4XX.

Considerando apenas o efeito do $\mathrm{Ni}$, a evolução na variação de eficiência aumentou em 18\% comparando o ano de 2011 com 2012 e 156\% comparando 2011 com 2013.

\section{Agradecimentos}

Os autores agradecem a toda equipe da Aciaria da Aperam South América que comprometeu durante todo o trabalho o que garantiu a sustentabilidade do projeto.

* Contribuição técnica ao $45^{\circ}$ Seminário de Aciaria - Internacional, 25 a 28 de maio de 2014, 


\section{BIBLIOGRAFIA}

1 Araujo LA. Manual de Siderurgia - Produção. vol.1. São Paulo: Editora Arte \& Cultura; 1997.

2 Rizzo, Ernandes. Introdução aos Processos de refino primário dos aços nos fornos elétricos a arco [apostila de curso]. São Paulo: Associação Brasileira de Metalurgia e Materiais; 2006.

3 Rizzo SEM. Introdução aos processos de preparação de matérias-primas para o refino de aços. São Paulo: Associação Brasileira de Metalurgia e Materiais; 2005.

4 Werkema MCC. Ferramentas estatística básica para o gerenciamento de processo. Belo Horizonte: Fundação Christiano Ottoni, Escola de Engenharia da UFMG; 1995.

5 Paris WS. Proposta de uma metodologia para identificação de causa raiz e solução de problemas complexos em processos industriais: um estudo de caso. Paraná: Ministério da educação, Universidade Federal do Paraná; 2003. p.111.

* Contribuição técnica ao $45^{\circ}$ Seminário de Aciaria - Internacional, 25 a 28 de maio de 2014, 